\title{
Effect of yoga practices on psycho-motor abilities among intellectually disabled children
}

\author{
Vishvanath Pise ${ }^{1}$, Balaram Pradhan ${ }^{1, *}$, Manmath Gharote ${ }^{2}$ \\ 'S-VYASA, Eknath Bhavan, Gavipuram Circle, Kempegowda Nagar, Bangalore, India \\ ${ }^{2}$ Lonavla Yoga Institute, Lonavla, Pune, India
}

The children with intellectual disabilities show disorders at motor development and coordination. Hence, the objective of this study was to see the effect of yoga practices on psycho-motor abilities of intellectually disabled children. Seventy intellectually disabled children were divided into experimental group and control group. Both experimental and control group were assessed on the first day and after 12 weeks of the yoga intervention for static balance, eye hand coordination, agility and reaction time. The subjects of experimental group then underwent a training of yoga practices, for $1 \mathrm{hr}$ for a total period of 12 weeks. The re- sult of within group comparison revealed significant improvement in static balance, eye hand coordination, agility, and reaction time $(P<$ 0.001 ) in subjects of yoga group however no change was observed in control group. The present study demonstrated that 12 weeks of yoga is effective in improving psycho-motor abilities of intellectually disabled children.

Keywords: Yoga, Intellectually disabled, Motor function

\section{INTRODUCTION}

Intellectual disability (ID) is characterized by below-average intelligence or mental ability and a lack of skills necessary for dayto-day living. People with intellectual disabilities can and do learn new skills, but they learn them more slowly. The child with intellectual disabilities shows disorders at bodily scheme, perceptive-motor development and coordination levels, but properly stimulated, he/she can reach significant progress in psychomotor and motor fields (Silvia and Ofelia, 2013). Earlier research studies indicate that adults with intellectual disabilities have significant health difference when compared with the general population. In fact, physical inactivity in adults with intellectual disabilities leads to obesity (Bhaumik et al., 2008; Melville et al., 2008), and higher rates of mortality (Lauer and McCallion, 2015).

The children with intellectual disabilities find difficulty in activities of daily living and functioning in society as the ability to learn and adapt to the changing environment is limited. As compared to other groups with disabilities these individuals have more functional limitations in adaptive behavior and motor function (Kubilay et al., 2011). Due to their ID the time taken to learn motor skills is prolonged. For children with mental retardation, fitness and overall functioning is lower as they are not active during the course of school day and have limited opportunities to participate in the physical activities available to their peers. Therefore, these children tend to be weaker and more susceptible to early fatigue than their peers (Campbell and Ball, 1978; Dichter et al., 1993; Durstine et al., 2000; Fernhall and Unnithan, 2002).

Moreover, children with intellectual disabilities have motor problems and higher-order cognitive deficits. Hartman et al. (2010) reported that intellectually disabled individuals scored lower on locomotor ability and object control. These results support the notion that besides being impaired in qualitative motor skills intellectually challenged children are also impaired in higher-order executive functions. Additionally, adolescents with ID have difficulty in making optimal use of their working memory when new or complex situations tax their abilities Van der Molen et al. (2010a). However, working memory can be effectively trained in adoles-
${ }^{*}$ Corresponding author: Balaram Pradhan (iD https://orcid.org/0000-0003-2314-2485 S-VYASA, Eknath Bhavan, Gavipuram Circle, Kempegowda Nagar, Bangalore, India

Tel: +91-8277908823, E-mail: balaramp13@gmail.com

Received: June 4, 2018 / Accepted: July 17, 2018
This is an Open Access article distributed under the terms of the Creative Commons Attribution Non-Commercial License (http://creativecommons.org/licenses/by-nc/4.0/) which permits unrestricted non-commercial use, distribution, and reproduction in any medium, provided the original work is properly cited. 
cents with mild to borderline intellectual disabilities Van der Molen et al. (2010b).

Nevertheless, several research studies demonstrated impact of physical activity/exercise on physical fitness, mental health, memory etc. in intellectually disabled individuals. For example, reaction time of children with mild ID significantly improved after twelve weeks of exercise program (Yildirim et al., 2010). Further, a critical review by Bartlo and Klein (2011) revealed moderate to strong evidence that physical activity intervention positively affected balance, muscle strength, and quality of life in individuals with ID.

Yoga is widely acknowledged as a feasible activity to engage inactive and sedentary individuals in physical activity. It requires minimal training, resources or expense and can be an appropriate activity for individuals with intellectual disabilities. The research literature indicates that yoga has the potential to improve health and functional capacity. At a basic level, yoga promotes physical fitness (Collins, 1998; Gharote, 1976; Telles et al., 1993) by promoting increased muscle strength (Raub, 2002), flexibility (Armstrong and Smedley, 2003; Ray et al., 2001), and stability (Telles et al., 1993). Further it was found that yoga practices improve intelligent quotient (IQ) and social adaptation parameters (Uma et al., 1989). Although previous research studies indicate beneficial effects of yoga however, there are very limited studies conducted to examine the efficacy of yoga practices among intellectually disabled children. Therefore, the main objective of this study is to see the effect of yoga practices on motor function of intellectually disabled children.

\section{MATERIALS AND METHODS}

\section{Participants}

Participants were children attending school for intellectually disabled individuals situated in Pune, Maharashtra. The participants were classified as mild to moderate ID on the basis of IQ score. Participant's age ranged from 10 to 15 years were included.

\section{Research design}

Quasi experimental pre-post design was used for conducting this research study. The purposive sample was randomly assigned into experimental group ( $\mathrm{n}=35 ; 25$ males and 11 females) and control ( $\mathrm{n}=35 ; 20$ males and 17 females) group by Chit method for random selection. Both experimental and control groups were assessed on the first day and after 12 weeks of the interventions. The subjects of experimental group then underwent a training of yoga practices, under the supervision of a yoga expert, for $1 \mathrm{hr}$ in the evening, excluding Saturdays, Sundays, and holidays for a total period of 12 weeks. The control group did not undergo any yoga training during this period. However, both the groups continued to participate in their regular extracurricular activities during school hours. There were 35 subjects in each group at the baseline testing. However, at the end of 12 weeks, there were 32 subjects in experimental group and 29 subjects in control group because of 9 drop-outs. Drop-outs were due to various reasons, mainly disinterest, illness and absence during either pretesting or post testing.

\section{Sample size}

On the conservative estimate, considering a moderate effects size, according to Cohen (1988), sample size was calculated. In order to achieve a minimum power of 0.80 , with alpha $=0.05$, for two groups, the required sample size was calculated as 29 subjects per group. However, in order to protect against the effects of attrition on power, a minimum number of 35 subjects in each group was established. For all the above calculations, G*Power 3.0 was used, and alpha was fixed at 0.05 , power at 0.95 , and assuming two tailed condition. The subjects were selected from Sai Seva School for Mentally Challenged students and Kamayani School situated in Chinchwad and Pune respectively.

\section{Ethical consideration}

Signed informed consent was obtained from the parent or guardian of the child at the time of registration, after they had read the proposal that involves noninvasive data collection methods and risks free intervention. All procedures were reviewed and accepted by the institutional ethical committee of S-VYASA University. Participation in this project was voluntary in nature and participants were not provided with any incentives for their participation. Research participants were free to discontinue participation at any point in time without consequence. This was stated verbally to both the control and intervention groups during presentation to the parents of participants and school authorities. It was also restated in consent forms.

\section{Assessment}

Static balance was assessed by using standing stork test. The subjects were to stand comfortable with hands on the hips. Then they were asked to lift the right leg and place the sole of the right foot against the side of the left kneecap and close both eyes. Next on the command "Go" the stopwatch started and the subjects 
were instructed to raise the heel of the left foot to stand on the toes. When the subject touches left heel to the ground or the right foot moves away from the left knee the time was recorded in seconds.

Eye hand coordination was measured by using wall toss test. A mark was placed 2-m distance from the wall. The subject was asked to stand behind the line and facing the wall. The ball is thrown from one hand in an underarm action against the wall, and attempted to be caught with the opposite hand. The ball is then thrown back against the wall and caught with the initial hand. The test was continued for $30 \mathrm{sec}$. The successful catches in a 30-sec period was considered as a score.

Agility was assessed by using shuttle run test. This test requires the subject to run back and forth between two parallel lines as fast as possible. Two lines parallel to each other are placed on the floor 30 feet apart, 2 blocks of wood, $2 \times 2 \times 4$ inches and a stop watch are needed to conduct this test. The subjects were asked to stand at one of the lines with 2 blocks at the other line. On the signal 'to start,' the subject start running to the block which he carries across the starting line and places the block which he carries across the starting line on his way back. The score was the time recorded in seconds.

Reaction time was assessed by using ruler test. To begin the test ruler was held by the experimenter between the outstretched index finger and thumb of the subject's dominant hand. The ruler was held such that the top of the subject's thumb is at the $0-\mathrm{cm}$ line. The experimenter instructs the subject to catch the ruler as soon as possible after it has been released.

The experimenter releases the ruler and the subject catches the ruler between their index finger and thumb as quick as possible. The distance between the bottom of the ruler and the top of the subjects thumb where the ruler has been caught was recorded.

\section{Intervention}

The yoga training consisted of Loosening Exercises, Asana, Pranayama, and Meditation. All practices were introduced in a slow and progressive manner. Yoga training was for $1 \mathrm{hr}$, for 6 days in a week for 12 weeks. The experimental group practiced Yoga asanas (postures) and Pranayama (breathing techniques). Each asana pose was held for 15-30 sec initially, and for $1 \mathrm{~min}$ in the later stages. Duration of Pranayama was 2-3 min initially and was gradually increased to $5 \mathrm{~min}$. The loosening exercises included were hand rotation front \& back, twisting, side arch hand right \& left, forward \& backward bending and side bending. Each exercise was performed for 2 min with 10 rounds each. Standing asana include Ardhakati
Chakrasana, Ardha Chakrasana, Padahastasana, Trikonasana, Tadasana, and Adhomukha Shwanasana. The sitting position asana were Vajrasana, Janu Shirasana, Ushtrasana and Vakrasana. The supine pose asana practiced were Ardha Halasana, Halasana, Pawanmuktasana, Setu Bandhasana, and Shavasana. The prone position asana included were Bhujangasana, Dhanurasana, and Makarasana. The breathing exercises for experimental group participants were Bhastrika, dirgha swasana, and Bhramari pranayama.

\section{Statistical analysis}

Standard methods were followed for the data extraction for each of the variables. Data analysis was done using SPSS ver. 16.0 (SPSS Inc., Chicago, IL, USA). Data was analyzed using paired $t$-tests, independent $t$-test and descriptive statistical method.

\section{RESULTS}

The base line demographic data of age, height, and BMI of the groups are given in Table 1. The outcomes of within group and between group analyses of motor fitness parameters, for the Yoga and control groups have been presented in Tables 2, 3, respectively.

Results of paired sample $t$-test in experimental group showed significant change in static balance $(t=9.47, d f=31, P<0.001)$; eye hand coordination $(t=12.14, d f=31, P<0.001)$; agility $(t=3.41, d f=31, P<0.001)$ and reaction time $(t=11.84, d f=31$, $P<0.001)$ after yoga training intervention. Further, results of paired sample $t$-test in control group revealed no significant change in Static balance $(t=0.91, d f=28, P>0.05)$; agility $(t=1.81, d f=28, P>0.05)$ and reaction time $(t=-0.54, d f=28$, $P>0.05)$ after controlled period of three months. However, significant increase in eye hand coordination $(t=-2.94, d f=28, \mathrm{n}=29$, $P<0.01)$ was observed in control group participants.

The result of between group comparison revealed that experimental group had significant change in static balance $(t=4.56, P>$ $0.001)$ and reaction time $(t=8.14, P>0.001)$ as compared to control group participants. However, no significant change in agility $(t=0.90, P>0.05)$ and eye hand coordination $(t=1.83, P>0.05)$ was observed in experimental group as compared to control group.

Table 1. Demographic characteristics of participants

\begin{tabular}{lcc}
\hline Variable & Yoga group $(\mathrm{n}=32)$ & Control group $(\mathrm{n}=29)$ \\
\hline Height $(\mathrm{cm})$ & $139.53 \pm 11.47$ & $142.75 \pm 13.52$ \\
Weight $(\mathrm{kg})$ & $35.03 \pm 9.96$ & $36.81 \pm 13.30$ \\
Body mass index $\left(\mathrm{kg} / \mathrm{m}^{2}\right)$ & $17.69 \pm 3.37$ & $17.96 \pm 3.93$
\end{tabular}

Values are presented as mean \pm standard deviation. 
Table 2. Descriptive statistics and $t$-test results for within group comparison in motor function tests

\begin{tabular}{|c|c|c|c|c|c|}
\hline Variable & Pre & Post & $t$ & Sig. & $95 \%$ Cl for mean \\
\hline \multicolumn{6}{|l|}{ Yoga group } \\
\hline Static balance (sec) & $3.22 \pm 2.92$ & $5.94 \pm 3.51$ & -9.47 & 0.001 & -3.29 to -2.12 \\
\hline Eye hand coordination (n) & $16.03 \pm 8.38$ & $26.06 \pm 8.93$ & -12.14 & 0.001 & -11.71 to -8.34 \\
\hline Agility (sec) & $23.21 \pm 7.38$ & $18.71 \pm 5.35$ & 3.41 & 0.002 & $1.81-7.18$ \\
\hline Reaction time (sec) & $0.31 \pm 0.02$ & $0.22 \pm 0.03$ & 11.84 & 0.001 & $0.07-0.10$ \\
\hline \multicolumn{6}{|l|}{ Control group } \\
\hline Static balance (sec) & $2.92 \pm 1.95$ & $2.68 \pm 1.89$ & 0.94 & 0.354 & $0.28-0.78$ \\
\hline Eye hand coordination (n) & $16.48 \pm 6.50$ & $21.34 \pm 10.94$ & 2.94 & 0.006 & -8.23 to -1.48 \\
\hline Agility (sec) & $20.06 \pm 5.09$ & $20.81 \pm 5.32$ & -1.81 & 0.080 & -1.59 to 0.09 \\
\hline Reaction time (sec) & $0.30 \pm 0.03$ & $0.30 \pm 0.04$ & -0.54 & 0.589 & -0.01 to 0.01 \\
\hline
\end{tabular}

Values are presented as mean \pm standard deviation.

$\mathrm{Cl}$, confidence interval.

Table 3. Results of independent sample t-test between yoga and control group in motor function tests

\begin{tabular}{lccccc}
\hline Variable & Yoga-Final $(\mathrm{n}=32)$ & Control-Final $(\mathrm{n}=29)$ & $t$ & Sig. (2-tailed) & Difference in mean 95\% Cl \\
\hline Static balance $(\mathrm{sec})$ & $5.94 \pm 3.51$ & $2.68 \pm 1.89$ & 4.56 & 0.000 & $3.25(1.82-4.69)$ \\
Eye hand coordination $(\mathrm{n})$ & $26.06 \pm 8.93$ & $21.34 \pm 10.94$ & 1.83 & 0.072 & $4.71(0.44-9.87)$ \\
Agility (sec) & $18.71 \pm 5.35$ & $20.81 \pm 5.32$ & 0.90 & 0.131 & $2.09(-4.83$ to 0.64$)$ \\
Reaction time (sec) & $0.22 \pm 0.03$ & $0.30 \pm 0.04$ & -8.14 & 0.000 & $0.08(-0.10$ to 0.06$)$ \\
\hline
\end{tabular}

Values are presented as mean \pm standard deviation.

$\mathrm{Cl}$, confidence interval.

These results indicate that yoga practices are effective in improving motor function of intellectually disabled children.

\section{DISCUSSION}

The findings of this 12-week research study suggest, amply, the effectiveness of yoga training in improving motor function of intellectually disabled children. Previous studies have indicated that individuals with intellectual disabilities score lower on reaction time than do individuals without an ID (Baumeister et al., 1965; Brewer and Nettelbeck, 1977; Un and Erbahçeci, 2001). Further, children with ID had significantly more borderline and definite motor problems than the normative sample and there is an association between degree of ID and performance of manual dexterity, ball skills and balance skills (Vuijk et al., 2010). For this reason, individuals who are intellectually disabled are often unable to adequately perform everyday activities and are limited in their work-related duties (Fernhall and Pitetti, 2001).

The results of this study showed improvement in motor skills such as reaction time, eye hand coordination, static balance, and agility after 3 months of yoga training. In fact, yoga for children is a relaxation technique that has been found to reduce stress and tension, dissipate excess energy, relieve tiredness, lengthen attention span, improve physical health, sharpen concentration, enhance mental clarity, and cultivate better interpersonal relationships (Peck et al., 2005; Seiler and Renshaw, 1978; Telles et al., 1993). Yoga is a complete science, which makes the body healthy and provides mental peace leading to spirituality. It is very useful for the disabled as they can get relief from physical ailments (Ijbarathi, 2012), improves IQ, concentration, attention span, psycho-motor coordination (Uma et al., 1989). The findings of present study are supported by earlier research reports. In fact, Yoga training for a period of 3 months helped to improve selected motor function tests. The appearance of such result may be due to the fact that asanas, pranayamas, bandhas, and kriyas which generally give gentle massage to the inner muscles and cleans their impurities. Regular practice of such yogic exercises might have helped to improve overall performance of the muscles and joints and therefore results into the enhanced level of gross motor function abilities.

\section{CONFLICT OF INTEREST}

No potential conflict of interest relevant to this article was reported. 


\section{REFERENCES}

Armstrong WJ, Smedley JM. Effects of a home-based yoga exercise program on flexibility in older women. Clin Kinesiol 2003;57:1-6.

Bartlo P, Klein PJ. Physical activity benefits and needs in adults with intellectual disabilities: systematic review of the literature. Am J Intellect Dev Disabil 2011;116:220-232.

Baumeister AA, Hawkins WF, Kellas G. Reaction speed as a function of stimulus intensity in normals and retardates. Percept Mot Skills 1965; 20:649-652.

Bhaumik S, Watson JM, Thorp CF, Tyrer F, McGrother CW. Body mass index in adults with intellectual disability: distribution, associations and service implications: a population-based prevalence study. J Intellect Disabil Res 2008;52(Pt 4):287-298.

Brewer N, Nettelbeck T. Influence of contextual cues on the choice reaction time of mildly retarded adults. Am J Ment Defic 1977;82:37-43.

Campbell J, Ball J. Energetics of walking in cerebral palsy. Orthop Clin North Am 1978;9:374-377.

Cohen J. Statistical power analysis for the behavioral sciences. 2nd ed. Hillsdale (NJ): Lawrence Erlbaum Associates; 1988.

Collins C. Yoga: intuition, preventive medicine, and treatment. J Obstet Gynecol Neonatal Nurs 1998;27:563-568.

Dichter CG, Darbee JC, Effgen SK, Palisano RJ. Assessment of pulmonary function and physical fitness in children with Down syndrome. Pediatr Phys Ther 1993;5:3-8.

Durstine JL, Painter P, Franklin BA, Morgan D, Pitetti KH, Roberts SO. Physical activity for the chronically ill and disabled. Sports Med 2000; 30:207-219.

Fernhall B, Pitetti KH. Limitations to physical work capacity in individuals with mental retardation. Clin Exerc Physiol 2001;3:176-185.

Fernhall B, Unnithan VB. Physical activity, metabolic issues, and assessment. Phys Med Rehabil Clin N Am 2002;13:925-947.

Gharote ML. Effect of yoga exercises on failures on the Kraus-Weber tests. Percept Mot Skills 1976;42:654.

Hartman E, Houwen S, Scherder E, Visscher C. On the relationship between motor performance and executive functioning in children with intellectual disabilities. J Intellect Disabil Res 2010;54:468-477.

Ijbarathi. Yoga: a ray of hope. Mumbai (India): Complete Wellbeing Publishing Private Ltd.; 2012.

Kubilay NS, Yildirim Y, Kara B, Harutoglu Akdur H. Effect of balance training and posture exercises on functional level in mental retardation. Fizyoter Rehabil 2011;22:55-64.
Lauer E, McCallion P. Mortality of people with intellectual and developmental disabilities from select US state disability service systems and medical claims data. J Appl Res Intellect Disabil 2015;28:394-405.

Melville CA, Cooper SA, Morrison J, Allan L, Smiley E, Williamson A. The prevalence and determinants of obesity in adults with intellectual disabilities. J Appl Res Intellect Disabil 2008;21:425-437.

Peck HL, Kehle TJ, Bray MA, Theodore LA. Yoga as an intervention for children with attention problems. Sch Psychol Rev 2005;34:415-424.

Raub JA. Psychophysiologic effects of Hatha Yoga on musculoskeletal and cardiopulmonary function: a literature review. J Altern Complement Med 2002;8:797-812.

Ray US, Mukhopadhyaya S, Purkayastha SS, Asnani V, Tomer OS, Prashad R, Thakur L, Selvamurthy W. Effect of yogic exercises on physical and mental health of young fellowship course trainees. Indian J Physiol Pharmacol 2001;45:37-53.

Seiler G, Renshaw K. Yoga for kids. Elem Sch Guid Couns 1978;12:229237.

Silvia T, Ofelia P. Aspects on the motor and psychomotor development of the child with intellectual disabilities. Sci Movem Health 2013;13:551557.

Telles S, Hanumanthaiah B, Nagarathna R, Nagendra HR. Improvement in static motor performance following yogic training of school children. Percept Mot Skills 1993;76(3 Pt 2):1264-1266.

Uma K, Nagendra HR, Nagarathna R, Vaidehi S, Seethalakshmi R. The integrated approach of yoga: a therapeutic tool for mentally retarded children: a one-year controlled study. J Ment Defic Res 1989;33(Pt 5): 415-421.

Un N, Erbahçeci F. The evaluation of reaction time on mentally retarded children. Pediatr Rehabil 2001;4:17-20.

Van der Molen MJ, Van Luit JE, Van der Molen MW, Jongmans MJ. Everyday memory and working memory in adolescents with mild intellectual disability. Am J Intellect Dev Disabil 2010a;115:207-217.

Van der Molen MJ, Van Luit JE, Van der Molen MW, Klugkist I, Jongmans MJ. Effectiveness of a computerised working memory training in adolescents with mild to borderline intellectual disabilities. J Intellect Disabil Res 2010b;54:433-447.

Vuijk PJ, Hartman E, Scherder E, Visscher C. Motor performance of children with mild intellectual disability and borderline intellectual functioning. J Intellect Disabil Res 2010;54:955-965.

Yildirim NU, Erbahçeci F, Ergun N, Pitetti KH, Beets MW. The effect of physical fitness training on reaction time in youth with intellectual disabilities. Percept Mot Skills 2010;111:178-186. 